\title{
Estimation of the influence of a defect on the operational suitability of a pipeline
}

\author{
A.A. Tarasenko ${ }^{1}$, P.V. Chepur ${ }^{1}$, and A.A. Gruchenkova ${ }^{2, *}$ \\ ${ }^{1}$ Industrial University of Tyumen, 625000 Volodarskogo Street 38, Russia \\ ${ }^{2}$ Surgut Oil and Gas Institute, 628405 Entuziastov Street 38, Russia
}

\begin{abstract}
A finite-element model of a pipe header with a defect in the metal wall was created in the ANSYS software complex. The boundary conditions consider the hinging of the ends of the section from linear displacements. The calculation is based on the procedure of the allowable conditional elastic stresses. Values of equivalent stresses arising in the defective pipeline from the operational loads are obtained. Analysis of the obtained stresses in comparison with the allowable values is given based on the calculated resistance of steel. It is established that a dent in the pipeline causes a local stress perturbation. Thus, an increase in equivalent stresses in the region of the maximum depth of the dent amounted to $1.3 \%$ in comparison to the vicinity of the defect. Maximum values of membrane, tangential, and equivalent stresses do not exceed the design resistance. A conclusion is drawn on the influence of the dent-type defect on the operational suitability of the pipeline under study.
\end{abstract}

\section{Introduction}

When carrying out technical inspection of process pipelines at oil transportation facilities, there is often a problem of assessing their technical condition and the possibility of further operation [1-3]. As a result of the diagnostics of the large tank RVSPK-100000, a defect of the dent type was found in the near-weld zone of the process pipeline (Figure 1). According to preliminary estimates, there is no combination of external operational loads that can cause the onset of the limiting state in the tank pipe header. According to [4-5], it is allowed to perform specifying calculations based on the results of diagnostics of metal structures. In addition, the delivery time of the pipe header elements for its complete replacement did not allow timely fulfillment of the planned repair of the tank. It was decided to confirm by calculations the possibility of operating a pipe header with a dent, and coincide its replacement with the next major repairs.

The purpose of this calculation is to determine the possibility of further operation of a pipeline with a defect of this type by establishing the values of the internal forces acting in the defective area and comparing the obtained values of the maximum stresses with the design resistances of the pipeline material. The state at which internal changes in the metal lead to its destruction is called the limit stress state. Conclusion on the reliability of the

\footnotetext{
*Corresponding author: alesya2010-11@yandex.ru
} 
structure should be made on the basis of a comparison of the maximum stresses that can occur at the most dangerous point, with the maximum allowable values for a given material. The limit stress state of a structure is the boundary beyond which its operation is unacceptable. The reliability of operation is the higher, the further from the limit state the level of actual stresses is inside the material of the part.

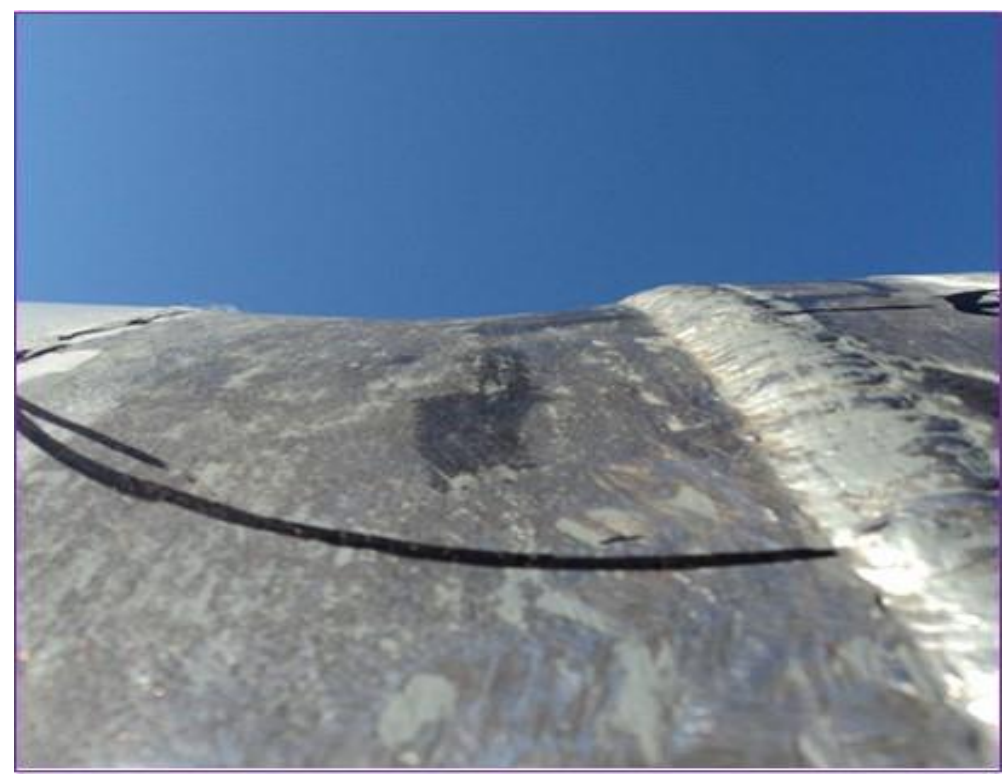

Fig. 1. The defect of the dent type in the near-weld zone of the process pipeline.

The values and nature of the distribution of stresses in the defective section of the pipeline are proposed to be determined by calculating the SSS of the model pipeline with a defect by the finite-element method in the ANSYS software package [6-8].

\section{Methods}

The calculation is based on the procedure $[9,10,11]$ of the allowable conditional elastic stresses. The stress-strain state of a defect of the dent type in the cylindrical shell of a pipe is determined by the spatial work of the calculation model under the action of combinations of operational loads.

Since the purpose of the work is to examine the stresses that arise in the region of the pipeline defect, the calculation model can be limited to the pipeline section containing the defect. Internal overpressure is the working load on the pipeline. Also, for calculations, you need the own weight of the pipe header, wind and snow load. Thus, to ensure the static definability of the model, the boundary conditions consider the hinging of the ends of the section from linear displacements.

The length of the shell should be chosen so that to eliminate the possibility of the influence of the endings on the defective area. An inward dent defect is modeled in accordance with the data of measurements during the diagnostics. The loads distributed on the shell area are applied to the shell section. Weld seams are neglected. When analyzing membrane stresses in ANSYS, SHELL181-type finite elements from the ANSYS library are used to model the shell [12-15].

To do this, the imported 3D model from the Autodesk AutoCAD software package is processed and optimized in the DesignModeller preprocessor in order to obtain surface 
elements. The finite element model consists of five shell objects, linked together by a bonded contact of the bonded type, i.e. a complete dependence of displacements in all nodes is ensured. The coordinate system is Cartesian.

The imposition of a finite-element grid is assumed to be free, repeating the curvature of the surface. The grid is superimposed automatically. The minimum size of the grid face of $0.6 \mathrm{~mm}$ was obtained during condensing in the vicinity of the defect. For other constructive elements, the grid size is assumed equal to $10 \mathrm{~mm}$ (Figure 2).

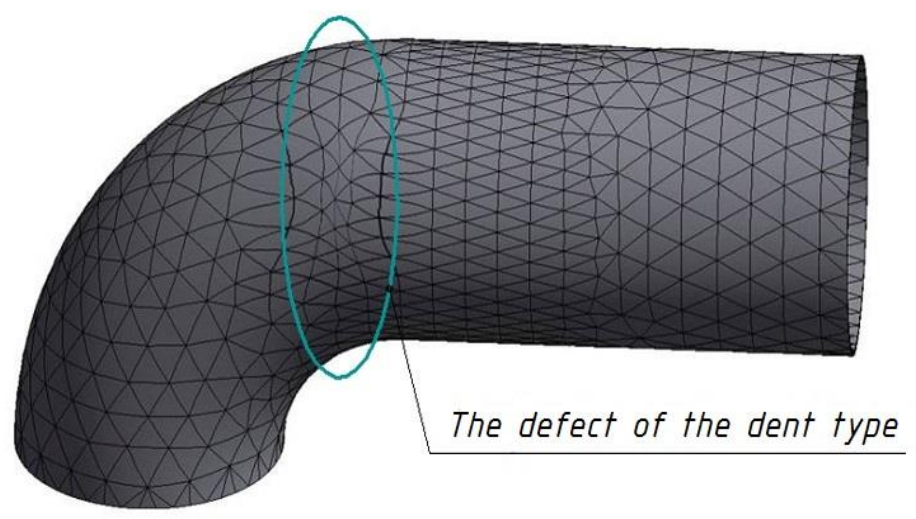

Fig. 2. The finite-element grid.

The nonlinear model is solved by iteration. Values of equivalent stresses are presented in the most loaded area of the section of the shell - the outer surface. Initial data for calculation: stored product - oil or water (for hydraulic tests), external diameter - $900 \mathrm{~mm}$, pipe wall thickness $-9.2 \mathrm{~mm}$, branch wall thickness $11.4 \mathrm{~mm}$, design internal pressure - 155 $\mathrm{kPa}$, specific gravity of steel $-7850 \mathrm{~kg} / \mathrm{m}^{3}$, modulus of elasticity of steel $-200000 \mathrm{MPa}$, Poisson's ratio - 0.3, linear dimensions of the defect $-110 \times 275 \mathrm{~mm}$, defect depth $-7 \mathrm{~mm}$.

\section{Results and discussion}

Figures 3-5 present the calculation results in the form of graphic images of the stress distribution fields in the pipeline wall.

Based on the results of calculations, the following stresses were obtained: the maximum value of the membrane stresses in the defect region $\left(\sigma_{\mathrm{m}}\right)$ is $14.3 \mathrm{MPa}$, the maximum value of the membrane stresses outside the defect area $\left(\sigma_{\mathrm{m}}\right)$ is $8.1 \mathrm{MPa}$, the maximum value of the equivalent von Mises stresses in the defect region $\left(\sigma_{\mathrm{e}}\right)$ is $12.3 \mathrm{MPa}$, the maximum value of the equivalent von Mises stresses outside the defect area $\left(\sigma_{\mathrm{e}}\right)$ is $9.6 \mathrm{MPa}$ (Table 1$)$.

Table 1. The ratio of the effective equivalent stresses to the design resistance of the pipeline steel.

\begin{tabular}{|l|c|c|}
\hline \multicolumn{1}{|c|}{ Type of stresses } & Ratio & $\begin{array}{c}\text { Value of stresses, } \\
\text { MPa }\end{array}$ \\
\hline $\begin{array}{l}\text { The membrane stresses in the defect } \\
\text { region }\end{array}$ & $7.13 \%$ & 14.3 \\
\hline $\begin{array}{l}\text { The membrane stresses outside the } \\
\text { defect area }\end{array}$ & $4 \%$ & 8.1 \\
\hline $\begin{array}{l}\text { The equivalent von Mises stresses in } \\
\text { the defect region }\end{array}$ & $6.45 \%$ & 12.3 \\
\hline $\begin{array}{l}\text { The equivalent von Mises stresses } \\
\text { outside the defect area }\end{array}$ & $5.1 \%$ & $9.6 \mathrm{MPa}$ \\
\hline
\end{tabular}




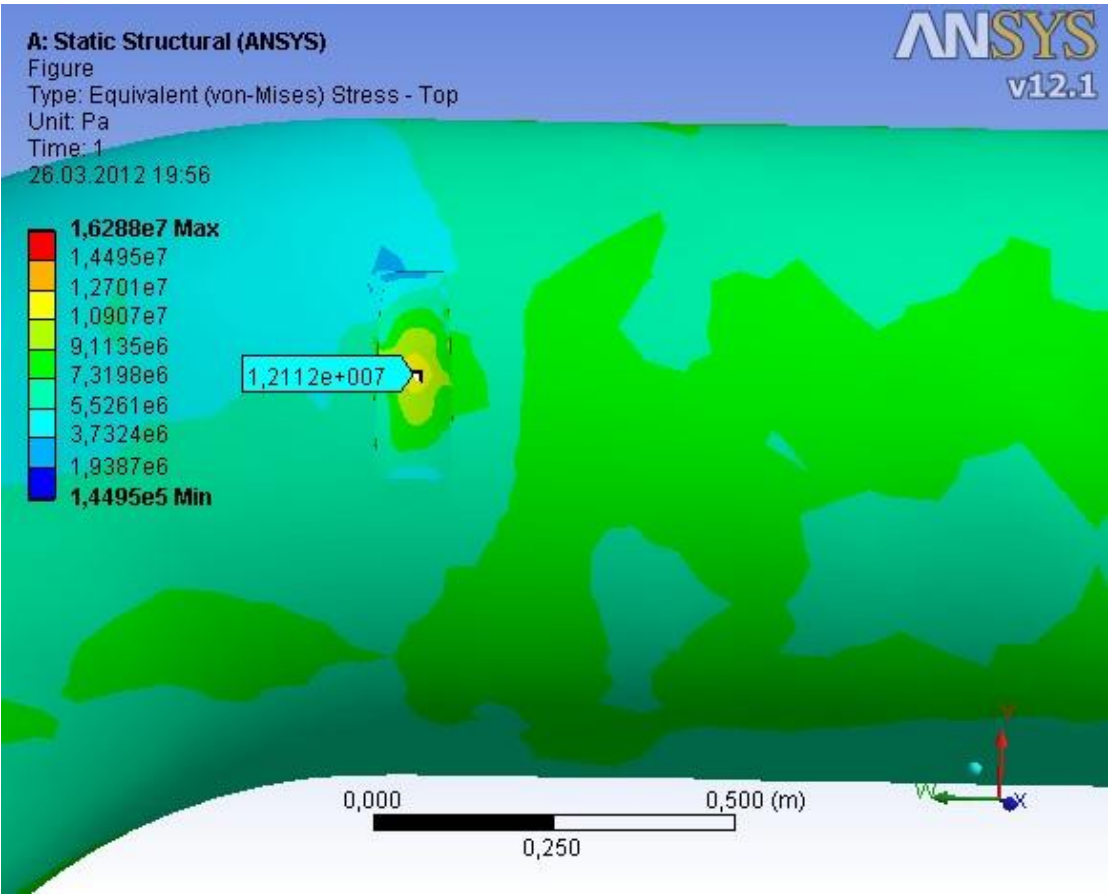

Fig. 3. Distribution of equivalent stresses in the defective pipe header.
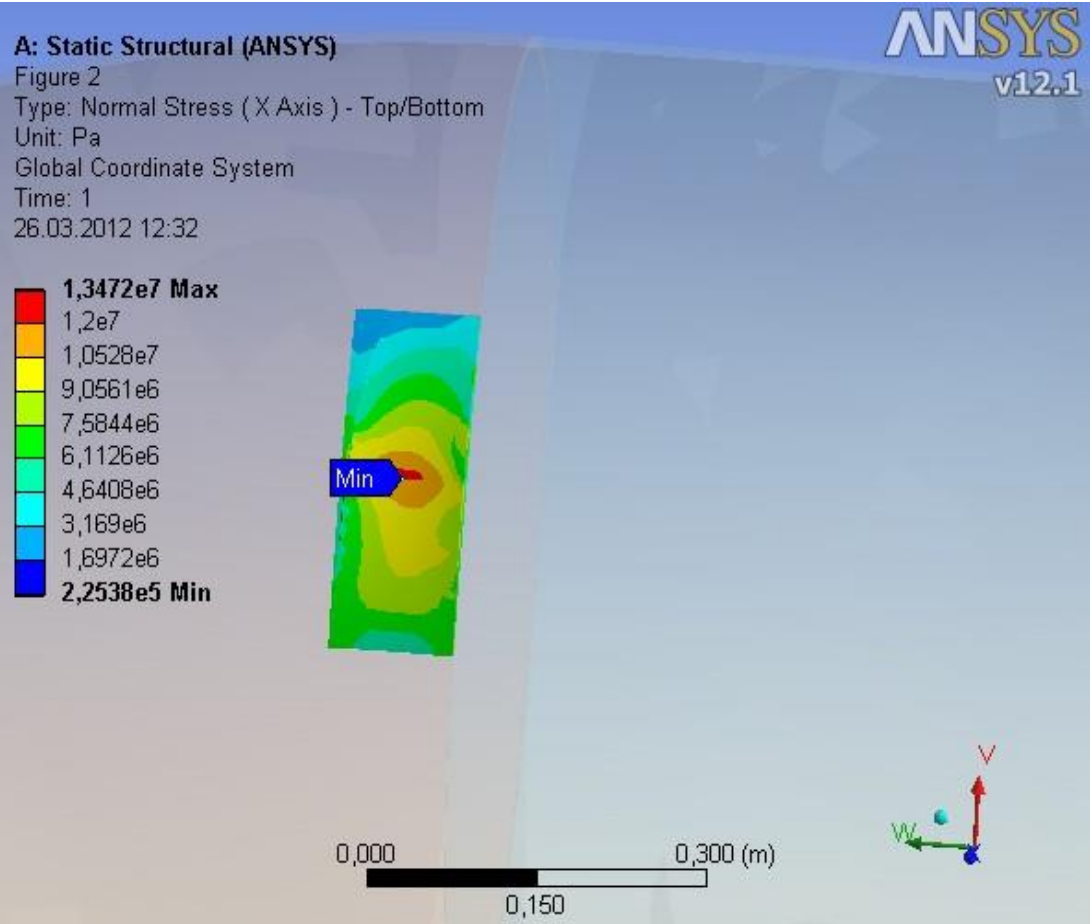

Fig. 4. Distribution of equivalent stresses in the defect area of the pipe header. 


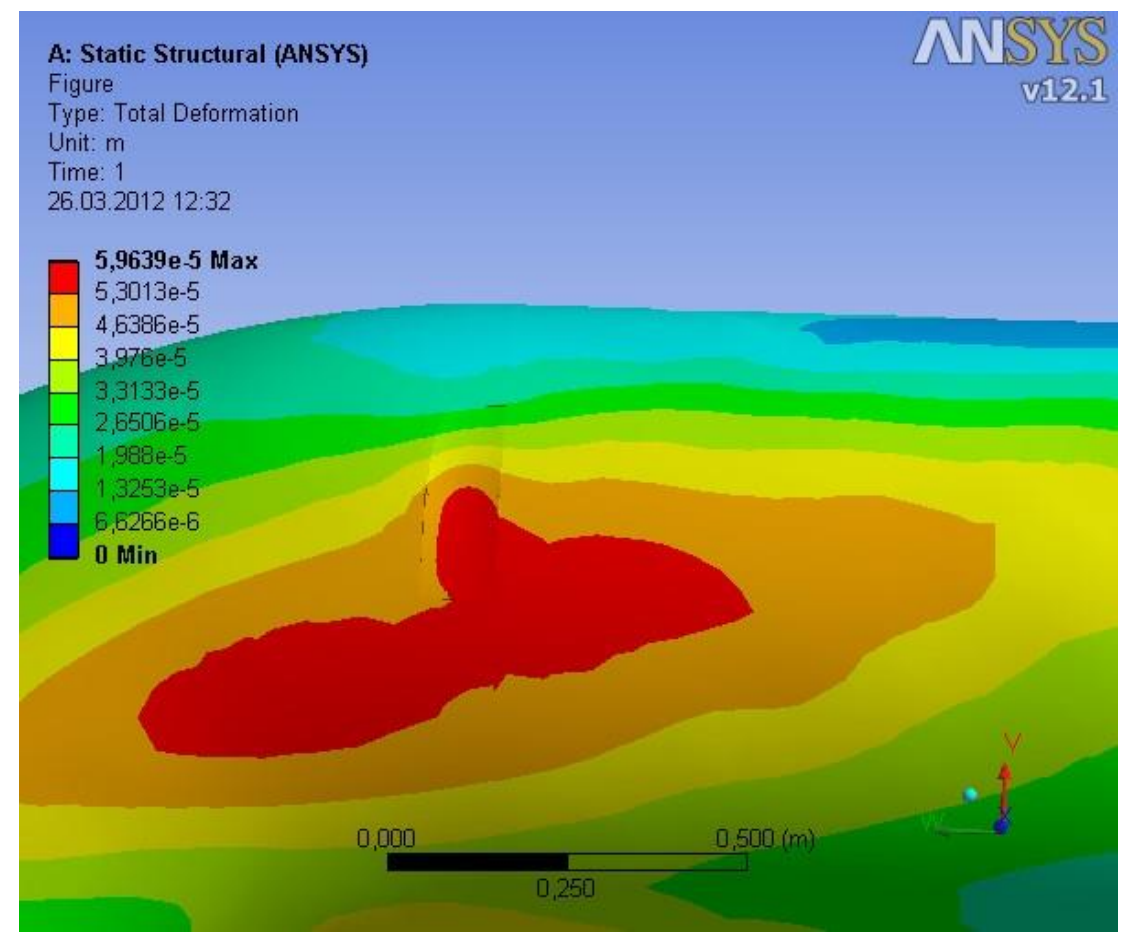

Fig. 5. Diagram of the deflection distribution in the defective pipe header.

\section{Conclusions}

The article presents a final-element model of the PRP-900 pipe header with a dent-type defect in the metal wall developed by the authors using the ANSYS software package. Equivalent stresses arising in the defective pipeline from the operational loads are $4 \%$ of the calculated resistance of steel. The dent in the pipeline causes a local stress perturbation. Thus, an increase in equivalent stresses in the region of the maximum depth of the dent amounted to $1.3 \%$ in comparison to the vicinity of the defect. Maximum values of membrane, tangential, and equivalent stresses do not exceed the design resistance of 189.58 MPa according to $[16,17]$. The condition of static strength is satisfied. Thus, at a design pressure of $155 \mathrm{kPa}$ within the pipe header pipeline with a wall thickness corresponding to the actual value, the strength of the pipeline is ensured and it can be said that there is no significant effect of the dent-type defect on the operational suitability of the pipeline under study.

Safe operation of the PRP-900 pipeline with a defect of the dent type is possible without limiting the operational loads, for a period until the next, complete diagnostics of the tank.

\section{Acknowledgments}

The paper was prepared within the implementation of the basic part of the government task for the project № 7.7858.2017/BP: "Development of the scientific principles of the techniques for determining the stress-strain state of the large-sized storage tanks during the differential settlement of the substructures and foundations". 


\section{References}

1. A.A. Tarasenko, M.N. Redutinskiy, P.V. Chepur, A.A. Gruchenkova, J. of Phys.: Conf. Series 1015, 032048 (2018)

2. A. Tarasenko, P. Chepur, A. Gruchenkova, AISC 692, 936-943 (2018)

3. S. Chirkov, A. Tarasenko, P. Chepur, IOP Conf. Series: Earth and Environ. Sci. 90, $012102(2017)$

4. RD-23.020.00-KTN-271-10, Pravila tekhnicheskoy diagnostiki rezervuarov (OAO AK "Transneft", Moscow, 2010)

5. RD-23.020.00-KTN-283-09, Pravila remonta i rekonstruktsii rezervuarov dlya khraneniya nefti ob"emom 1000-50000 kub. m. (OAO AK "Transneft", Moscow, 2009)

6. V.A. Bruyaka, V.G. Fokin, E.A. Soldusova, N.A. Glazunova, I.E. Adeyanov, Inzhenernyy analiz v ANSYS Workbench (Samara state technical University, Samara, 2010)

7. G.E. Korobkov, R.M. Zaripov, I.A. Shammazov, Chislennoe modelirovanie napryazhenno-deformirovannogo sostoyaniya $i$ ustoychivosti truboprovodov $i$ rezervuarov v oslozhnennykh usloviyakh ekspluatatsii (Nedra, Saint Petersburg, 2009)

8. A.V. Beloborodov, Vestnik of the Ural Fed. Univ. 1, 78-81 (2005)

9. A. Gruchenkova, A. Tarasenko, P. Chepur, D. Tarasenko, AIP Conf. Proc. 1800, 040019 (2017)

10. A. Tarasenko, P. Chepur, A. Gruchenkova, MATEC Web of Conf. 73, 01018 (2016)

11. A. Tarasenko, P. Chepur, S. Chirkov, AIP Conf. Proc. 1772, 060010 (2016)

12. A.A. Tarasenko, P.V. Chepur, Y. Guan, Oil Indust. 4, 134-136 (2016)

13. A.A. Tarasenko, P.V. Chepur, Soil Mech. and Found. Eng. 53(4), 238-243 (2016)

14. A.A. Tarasenko, A.A. Gruchenkova, M.A. Tarasenko, Oil Indust. 8, 132-135 (2016)

15. A. Tarasenko, A. Gruchenkova, P. Chepur, Proc. Eng. 165, 1125-1131 (2016)

16. Russian State Standard GOST 31385-2016

17. Russian State Standard GOST R 52910-2008 